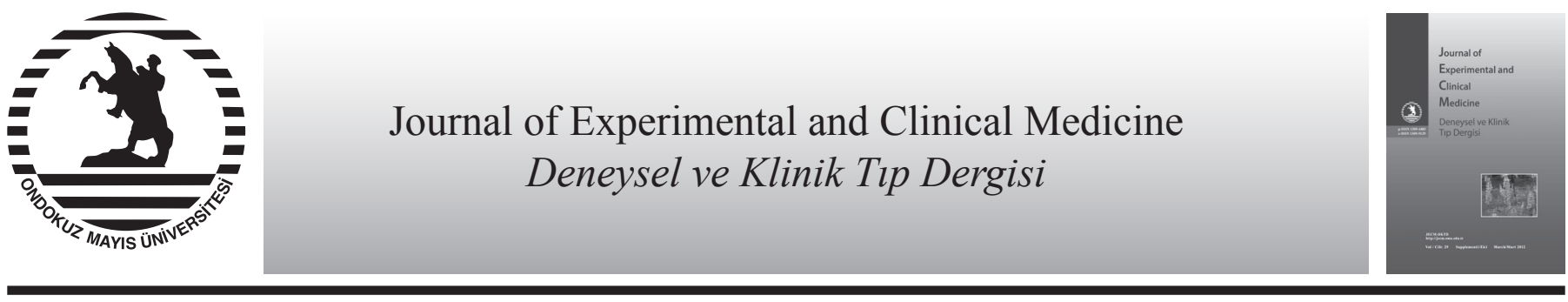

Derleme / Review

doi: $10.5835 /$ jecm.omu.29.s1.007

\title{
Tip 2 diabetes mellitus tedavisinde inkretinler
}

\author{
Incretins in the treatment of type 2 diabetes mellitus
}

\author{
Ramis Çolak* \\ Ondokuz Mayıs Üniversitesi, Tıp Fakültesi, Endokrinoloji ve Metabolizma Hastalıkları Bilim Dalı, Samsun, Türkiye
}

\begin{tabular}{|c|c|}
\hline \multicolumn{2}{|c|}{ MAKALE BİLGÍLERİ } \\
\hline Makal & \\
\hline Geliş & 13 / $01 / 2011$ \\
\hline Kabul & 15 / 02 / 2011 \\
\hline
\end{tabular}

\section{Yazışma Adresi:}

Ramis Çolak

Ondokuz Mayıs Üniversitesi Tıp Fakültesi

Endokrinoloji ve Metabolizma Hastalıkları

Bilim Dalı, Samsun,Türkiye

e-posta:ramis.colak@omu.edu.tr

\section{Anahtar Kelimeler:}

Diyabetes mellitus

İnkretinler

Eksenatid

Liraglutide

GLP-1 analogları

DPP-4 inhibitörleri

\section{Keywords:}

Diabetes mellitus

Incretins

Exenatide

Liraglutide

GLP-1 analogues

DPP-4 inhibitors

\section{ÖZET}

Bağırsaktan, besin alımı sonucu salgılanan hormonlar inkretin hormonlar olarak tanımlanmaktadır. İnkretin hormonlar glukagon benzeri peptit-1 (GLP-1) ve glukoz bağıml insülinotropik peptit (GIP) olarak adlandırılır. GLP-1, ileum ve kolonda yer alan L hücreleri, GIP ise bağırsağın daha üst bölgelerinde yerleşik K hücrelerinden salgılanır. İnkretin hormonlar pankreas beta hücrelerinden glukoz ile uyarılan insülin salgılanmasını artırır. Parenteral yolla kullanılan GLP-1 agonistleri olan Eksenatid ve Liraglutide kilo aldırmayı1, hipoglisemi yapmayıc1 ve hayvan deneylerinde ispatlanan beta hücre kütlesi ve ömrü üzerindeki olumlu etkileriyle, erken dönem diyabet tedavisinde kullanacağımız ilaçlar arasında yer almışlardır. Dipeptidil peptidaz-4 (DPP-4)inhibitörleri tek başına veya kombinasyon tedavisinde $\mathrm{HbAlC}$ yi düşürmede, açlık ve tokluk kan şekerleri seviyelerini düzenlemede etkili gözlenmişlerdir, ancak hipoglisemi ve kilo kaybı etkileri düşük izlenmiştir.

J. Exp. Clin. Med., 2012; 29:S30-S38

\section{ABSTRACT}

Incretin hormones are defined as intestinal hormones released in response to nutrient ingestion. The incretin hormones include glucagon-like peptide (GLP-1) and glucose dependent polypeptide (GIP). GLP-1 secreted by L cells from ileum and colon while GIP is maily produced $\mathrm{K}$ cells from the upper small intestine. Incretin hormones potentiate the glucose induced insulin response from pancreatic beta cells. With their non weight-gain, non hypoglycemic attributes and with positive effects on beta cell mass and lifetime as proven by animal experiments, parenterally used GLP-1 agonists of Exenatide and Liraglutide have emerged among medications used for the treatment of early stage diabetes. Dipeptidyl peptidase-4 inhibitors are effective either as a single or combination therapy in lowering glycated hemoglobin, fasting and postprandial glucose levels, with a low incidence of hypoglycemia and no weight gain.

J. Exp. Clin. Med., 2012; 29:S30-S38
İnkretinler gıda alımına cevap olarak gastrointestinal sistemdeki (GİS) özel hücrelerden salgılanan ve insülin sekresyonunu stimüle eden hormonlardır. İlk kez yirminci yüzy1lın başlarında gıda alınımına bağlı bazı intestinal faktörlerin salgılandığı ve bunların kan şekerini düşürücü etkileri olduğu yayınlanmış, 1930'larda bu faktörlere "inkretinler" adı verilmiştir. 1964 yılında oral olarak verilen glukozun, aynı miktarda intravenöz (iv) olarak verilen glukoza göre insülin cevabının daha fazla olduğu gösterilerek inkretinlerin etkisi açıklanmıştır (Elrick, 1964). İnkretinler gıda alınımı sırasında gastrointestinal kanaldan salgılanıp pankreas, mide, iskelet kasları, kalp akciğer ve beyindeki reseptörlerine bağlanır. İnkretin etkisi yemekten sonraki toplam insülin salınımının yaklaşık \%60'1ndan sorumludur.
Günümüzde inkretin etkiden iki hormon sorumlu tutulmaktadır. Bunlar glukoz bağımlı insülinotropik peptit (GIP) ve glukagon benzeri peptit-I (GLP-1) olarak isimlendirilir. Her ikisi de glukagon peptit ailesinin birer üyesidir ve aminoasit dizilimleri benzerlik gösterir. GLP-1 ve GIP glukoz homeostazında rol alan inkretinlerdir. GLP-1 ve GIP inkretin ailesine ait olan bağırsak kökenli polipeptidlerdir. Açlık durumunda plazma GIP ve GLP-I konsantrasyonu son derece düşüktür, öğün alımı ile birlikte hızla yükselir. Ancak salgılanan inkretin hormonlar, dipeptidil-peptidaz IV (DPP-4) enzimi tarafindan inaktif metabolitlerine hızla yıkılmaktadır, DPP-4 enzimi dokularda yaygın bir biçimde bulunur. Bağırsak mukozasının döküldüğü kan damarlarını döşeyen endotel hücrelerinin yüzeyinde de DPP-4 aktivitesi bulunur bu nedenle inkretin 
hormonların büyük bir kısmı daha sistemik dolaşıma ulaşamadan inaktive olmaktadır. Bu nedenle GIP'in yarı ömrü 5-7 dakika iken, GLP'nin plazmadaki yarı ömrü sadece 1-2 dakikadır. DPP-4 fizyolojik şartlar altında GLP-1 ve GIP'i ayıran ve dolayısıyla inaktive eden tek enzimdir (Vilsbøll ve Holst, 2004).

Gastrik inhibitör polipeptid veya glukoza bağımlı insülotropik polipeptid (GIP)

GIP gastrointestinal sistemin $\mathrm{K}$ hücrelerinden sekrete edilir. Bu hücreler en yoğun olarak deudenum ve jejenumda bulunur. GIP sekresyonu karbonhidrat, lipid ve protein içeren gıda alımından sonra stimüle olur. Tip 2 diyabette inkretin etkisi belirgin olarak azalmış olmasına rağmen GIP sekresyonu normaldir. Tip 2 diyabetli hastalarda gidalara GIP sekresyon cevabi hemen hemen normal sinırlarda iken, GIP etkisi belirgin olarak bozulmuştur. Bu nedenle günümüzde GIP, tip2 diyabette tedavi ajanı olarak kullanılamamaktadır.

\section{Glukagon-benzeri peptid-1 (GLP-1)}

Yirmi dokuz aminoasidli polipeptittir. Yemek sonrası öncül molekülü pro glukagon olan ve ileum distali ve kolonda lokalize L-hücrelerinden salgılanan bir inkretindir. DPP-4'le 2-4 dakikada metabolize edilir. GLP-1 etkisi, Tip 2 diabetes mellitusta (DM) korunmuştur. GLP-1 hem erken, hem de geç faz insülin cevabını arttırır. GLP-1'in terapötik potansiyeli hızlı inaktivasyon nedeniyle sınırlanmıştır. Hızlı inaktivasyon ve kısa eliminasyon yarılanma ömrü ( 1-2 dakika) nedeniyle GLP-1'in sürekli uygulanması gerekir, bu nedenle tip 2 diyabet gibi kronik bir hastalığın tedavisi için uygun değildir (Drucker, 2003).

\section{GLP-1' in etkileri}

Hipergliseminin azaltılmasında GLP-1'in çoklu etkileri vardır. Bunlar; glukoza bağımlı insülin sekresyonunun uyarılması, glukoza bağımlı glukagon sekresyonunun baskılanması, mide boşalmasının yavaşlatılması, $\beta$-hücre fonksiyonunun iyileştirilmesi, $\beta$-hücre kütlesi, fonksiyonu ve adacık hücresi neogenezinde artış yapması şeklindedir. Bunlara ek olarak, GLP-1 gıda alımında ve vücut ağırlığında azalma ile ilişkili bulunmuştur. GLP-1'in; $\beta$-hücrelerinde insülin üretimini ve $\beta$-hücresinin glukoza yanıtını artırdığı, $\beta$-hücre kaybını inhibe ettiği, $\beta$-hücre neogenezini artırdığı gösterilmiştir (Tourrel ve ark., 2002; Farilla ve ark., 2003; Kjems ve ark., 2003; Delmeire ve ark., 2004).

GLP-1 tip 2 DM'u olan hastalarda birden fazla metabolik etki göstermektedir. Tip 2 DM' lu hastalarda, GLP-1 infüzyonu glukoza bağımlı insülin sekresyonunu iyileştirmiş, plazma glukoz konsantrasyonlarını azaltmış ve açlık durumundaki ve post-prandiyal plazma glukoz düzeylerini ve HbA1C düzeylerini azaltmıştır. GLP-1 uygulaması ayrıca $\alpha$-hücrelerinin ve $\beta$-hücrelerinin glukoz duyarlılığını arttırmış, mide boşalması$\mathrm{n} ı$ inhibe etmiş ve iştah ve besin alımını azaltmıştır (Zander ve ark., 2002).

GLP-1, zucker diyabetik yağlı sıçanlarda $\beta$-hücresi kütlesini artırmıştır. Birçok klinik öncesi kanıt GLP-1'in, glukoz toleransının iyileştirilmesine ek olarak (Young ve ark., 1999), var olan $\beta$-hücrelerinin proliferasyonunu (Xu ve ark., 1999), adacık büyüklüğünde bir artışı (Stoffers ve ark., 2000) ve insandaki adacık projenitör hücrelerinin insülin üretici hücrelere farklılaşmasını (Abraham ve ark., 2002) tetiklediğini düşündürmektedir. GLP-1 reseptörleri olmayan farelerin glukozu tolere edemediği ve daha az sayıda $\beta$-hücresine sahip olduğu yönündeki gözlem tüm bu bulgular ile uyumludur $(\mathrm{Xu}$ ve ark., 1999).

GLP-1'in yıkılması: DPP-4 tarafindan enzimatik parçalanması GLP-1'i inaktive eder. GLP-1'in etkisini terapötik olarak oluşturmak için iki olası çözüm vardır:

1-Uzun etkili DPP-4-dirençli GLP-1 analogları/inkretin mimetikleri

2- DPP-4 inhibitörleri/inkretin güçlendiriciler.

\section{Inkretin mimetikler ve Tip 2 diyabet tedavisindeki yeri}

Tip 2 diyabetiklerde serum GLP-1 düzeyi iki şekilde artırılabilir; GLP-1'nin salınımından hemen inaktive edilmesini sağlayan DPP-4 enzimini bloke etmek veya DPP-4 enzimine dirençli uzun ömürlü GLP-1 reseptör agonistlerini kullanmaktır. Lilly tarafindan geliştirilen ilk GLP-1 reseptör agonisti eksenatid, FDA tarafindan 2005, EMEA tarafindan 2007 y1lında onaylanmış ve ülkemizde 2010 yılında kullanıma verilmiştir. Novo Nordisk'in geliştirdiği uzun ömürlü GLP-1 agositi liraglutide ise, 2008'de FDA ve EMEA tarafindan onaylanmış ve 2009 'da satışa sunulmuştur.

\section{Eksenatid (Eksendin-4)}

Güneybatı Amerika ve Kuzeydoğu Meksika'da yaşayan Gila canavarının (Heloderma suspectum) tükürüğünde bulunan bir proteinin sentetik versiyonudur. Gila canavarı tükrüğünden izole edilen 39 aminoasitlik exendin-4'ün, insan GLP1'i ile \%53 homoloji gösterdiği görülmüştür (Thorens 1993). Eksendin-4 DPP-4 y1kımına dirençlidir ve bu nedenle daha uzun yarı ömüre sahiptir (t 1/2 2-6 saat). "Eksenatid" olarak isimlendirilen sentetik exendin-4'ün pik düzeye ulaşması 2,1 saat, yarı ömrü 3,5-4 saattir. Subkutan injeksiyondan sonra 15 saate kadar plazmada saptanabilir. Ancak biyolojik yarı ömrü ortalama 8 saattir (Kolterman ve ark., 2005).

\section{Etki mekanizması}

In vitro, eksenatid rat adacıklarında GLP-1 reseptörlerine bağlanır (Kolterman ve ark., 2003). Eksdenatid GLP-1 gibi prediyabetik ve diyabetik ratlarda beta hücrelerinin yenilenmesini ve farklılanmasını uyardığı gözlenmiştir (Tang Cheristensen ve ark., 1996; Xu ve ark., 1999; Stoffers 2003). Eksenatid glukoz bağımlı olarak insülin sekresyonunu artırır. İnsülinotropik etkileri plazma glukozu yaklaşık $72 \mathrm{mg} / \mathrm{dl}$ 'de baskılanır (Egan, 2002). GLP-1 gibi eksenatid tip 2 diyabetli hastalarda; açlık glukozunu azaltır, postprandiyal hiperglisemiyi azaltır, birinci faz insülin yanıtını düzeltir, uygunsuz yüksek glukagon sekresyonunu baskılar, $\beta$-hücre iş yükünü azaltır, $\beta$-hücre duyarlılığını iyileştirir, mide boşalmasını yavaşlatır, gıda alımında azalma ve kilo kaybı sağlar. Hayvanlarda insülin üreten hücrelerde neogenezi ve proliferasyonu stimüle eder (Kolterman, 2003; De Fronzo ve ark., 2005).

\section{Kullanım şekli ve dozaj}

Başlangıç dozu 4 hafta süreyle günde iki kez $5 \mu \mathrm{g}, 4$ hafta sonra doz günde iki kez $10 \mu \mathrm{g}$ olacak şekilde artırılır. Günde iki kez $10 \mu$ g ile devam edilir. Bütün hastalar için sabit doz uygulaması vardır. Dozu belirlemek için ilave glukoz takibine gerek yoktur. Yemek miktarına veya egzersiz miktarına göre doz ayarlamasına gerek yoktur. Kahvaltıdan ve akşam yeme- 
ğinden önce veya iki enjeksiyon arasında en az 6 saat olacak şekilde öğle ve akşam yemeğinde önce uygulanır. Eksenatid yemekten önce, 1 saat içinde herhangi bir zamanda enjekte edilebilir. Eksenatid, yemeklerden sonra uygulanmamalıdır. Eğer hasta bir dozu yapmayı unutmuşsa yemekten sonra uygulanmamalı hasta bir sonraki yemekten önce normal dozunu yapmalidir.

\section{Klinik çalıșmalar}

Sülfonilüre ve metforminin maksimum dozda kullanım ile sülfonilüre, metformin veya glitazon kombinasyonu ile yeterli kontrol sağlanamayan hastalarda exenatide ilavesinin plasebo ile karşılaştırıldığı çalışmaların metaanalizlerinde plasebo ile karşılaştırıldığında eksenatid grubunda $\mathrm{HbAlC}$ değerlerinde büyük bir düşüş olduğu bidirilmiştir (Amori ve ark., 2007). Süresi 30 haftadan daha kısa olan çalışmalarda 2 yılda yaklaşık 5,4 kg ağırlık kaybının olduğu ve HbA1C' deki düşüşün devam ettiği gösterilmiştir (Ratner ve ark., 2006; Riddle, 2006). İnsülin glarjin ile karşılaştırmalı 32 hafta süreli çapraz çalışmada, başlangıç dönemi HbA1C düzeyi ne olursa olsun, Eksenatid'in her hasta grubunda insülin glarjin ile benzer glisemik etkinlik sağladığı gösterilmiştir (Barnett ve ark., 2007). Eksenatid HbA1C düzeylerinde, insülinlere benzer azalma sağlamıştır. İnsülin tedavisi alan gruplarda vücut ağırlığında anlamlı artış gözlenirken, eksenatid tedavisi alan hastalarda kilo kaybı sağlanmıştır (Heine ve ark., 2005; Barnett ve ark., 2007; Nauck ve ark., 2007).

Eksenatid ile insülin glarjinin karşılaştırıldığı çalışmada (Heine ve ark., 2005) 26 haftalık tedavinin sonunda her iki grupta $\mathrm{HbA1C}$ düzeylerinde benzer azalma sağlanmış ve hedef HbA1C düzeyine ulaşan hasta oranları da benzer olmuştur. Eksenatid insülin glarjine göre postprandiyal glukoz dalgalanmalarında daha fazla azalma sağlamıştır. İnsülin glarjin ile tedavi edilen hastalarda yemek öncesi glukoz düzeyleri daha düşük olurken, eksenatid ile tedavi edilen hastalarda ise yemek sonrası glukoz düzeyleri daha düşük olmuştur. 26 haftalık tedavi boyunca insülin glarjin grubundaki hastalarda kilo artışı gözlenirken, eksenatid grubundaki hastalarda kilo kaybı sağlanmıştır. Eksenatid ve insülin glarjin'in toplam hipoglisemi oranları düşüktür (sırasıyla 7,3 ve 6,3 olay/hasta y1l1). Eksenatid ile noktürnal hipoglisemi daha düșüktür. Gün içindeki hipoglisemiler insülin glarjin ile daha düşüktür. Her tedavi kolunda 4 ciddi hipoglisemi atağ 1 görülmüştür. Hiçbirisi medikal yardıma gerek duymamıştır. Hipoglisemi nedeniyle çalışmadan ayrılan olmamıştır.

Eksenatid monoterapide de kullanılabilir. Plasebo ile karşılaştırılan bir çalışmada eksenatid grubunda HbA1C, kilo ve kan basıncında de önemli düşüşler görülmüştür (Moretto 2008).Eksenatid tedavisi 3 yıl boyunca, kilo kaybını sürdürmüştür. Vücut ağırlığında başlangıca göre 30 . haftada 2,4 kg azalma ve 3. yılda 5,3 kg kayıp olmuştur (Klonoff ve ark., 2008). Üç yıl süreli Eksenatid tedavisi ile trigliserid düzeylerinde $\% 12$, total kolesterol düzeyinde $\% 5$, LDL-kolesterol düzeyinde $\% 6$ azalma ve HDL-kolesterol düzeyinde $\% 24$ artış sağlamıştır. Ayrıca sistolik kan basıncında \%2 ve diyastolik kan basıncında \%4 azalma gözlenmiştir.

Çift kör, randomize, çapraz bir çalışmada sitagliptin ile eksenatidin etki mekanizmaları karşılaştırılmıştır (DeFronzo ve ark., 2008). Eksenatid ile 2 saatlik post prandial glukoz (PPG) konsantrasyonu sitagliptine göre anlamlı düzeyde azalmıştır. Sitagliptin tedavisine göre, Eksenatid tedavisi; daha fazla azalma sağlamıştır. Zaman içinde PPG konsantrasyonları, postprandiyal glukoz dalgalanmaları, postprandiyal glukagon düzeyleri, insülinojenik indeksi iyileştirmiştir, mide boşalmasını geciktirmiştir, kalori alımını azaltmıştır

\section{Yan etkiler}

Eksenatidin yan etkileri daha çok gastrointestinal sistemle ilgilidir. Sülfonilürelerle birlikte kullanıldığında hafif-orta hipoglisemi görülebilir.

\section{GíS' teki yan etkileri}

Bulantı en sık rastlanan yan etkidir. Fakat genellikle hafif veya orta şiddetlidir. Tedavinin süresiyle azalmaktadır (Kendall 2005; Zinman ve ark., 2007). Bulantı doz titrasyonuyla azalabilmektedir (Fineman ve ark., 2004). Eksenatid ile tedavi edilen hastalarda nadir, spontan olarak bildirilen pankreatit olguları olmuştur. Preklinik toksikoloji çalışmalarında pankreatit kanıtı görülmemiştir. Klinik geliştirme aşamasında eksenatid ile gözlenen pankreatit insidansı ( 7 olgu;1,8/1000 birey yıl1) plasebo (1 olgu;2,7/1000 birey) ya da insülin tedavisi (1 olgu;1,4/1000 birey yılı) ile gözlenen insidansa benzerdir (Steinberg ve Tenner 1994; Fagenholz ve ark., 2007; Noel ve ark., 2009). İlaca bağlı pankreatit görece nadir olaydır (tüm vakaların \%1,4 ila \%2,0'si) T2DM'li hastalarda son zamanlarda yapılan epidemiyolojik bir çalışma T2DM'li hastaların diyabeti olmayanlara göre 3 kat daha fazla pankreatit geliştirme riski olduğunu belirtmiştir. Eksenatid ile akut pankreatit arasındaki ilişkiyi tam olarak değerlendirmek için daha kapsamlı farmako epidemiyolojik çalışmalar gerekmektedir. Devam eden şiddetli abdominal ağrıları olan hastalarda pankreatit düşünülmelidir. Bu gibi hastalarda eksenatid kesilmelidir. Eğer pankreatit doğrulanırsa eksenatid yeniden başlanmamalıdır.

\section{Anti-eksenatid antikorları}

Otuzuncu haftada hastaların \%38'inde düşük titreli antieksenatid antikorları gözlenmiştir. Bu gruptaki hastaların HbA1C değerleri antikor gözlenmeyenlerinki ile benzer düzeyde bulunmuştur. Otuzuncu haftada hastaların \%6'sında yüksek titreli antikor gözlenmiştir. Kontrollü çalışmalarda eksenatid verilen hastaların \%3'ünde glisemik kontrol bozulmuştur. Anti-eksenatid antikorları gelişen hastalardaki yan etki olay sıklığı ve tipi, antikor gelişmeyenlerinki ile benzer olarak bildirilmektedir. (Moretto ve ark. 2008)

\section{Uzun etkili GLP-1 analogları \\ Liraglutid}

Liraglutide bir GLP-1 analoğudur. Lipid yan zinciri arac1lığ 1 ile serum albuminine non kovalent olarak bağlanarak modifiye edilmiştir. Bunun sonucu daha yavaş yıkıma uğrar (Elbrønd 2002). GLP-1 ile \%97 homoloji gösterir. Molekül özelliği nedeniyle albumine daha sıkı bağlanır ve böylece DPP-4 aktivitesine daha dirençlidir. Bu nedenle yarılanma ömrü daha uzun olup-yaklaşık 12 saat-günde tek doz uygulanabilir. Tip 2 diyabetik hastalarda oral ajanlarla kombinasyonda veya diyet ve eksersizle birlikte kullanılabilir.

Liraglutid prefil kalemlerle uygulanır. Başlangıç dozu 0,6 mg. Bir hafta için günde bir kez cilt altı enjeksiyon şeklinde uygulanır (GISS yan etkileri azaltmak için) bir hafta sonra doz 1,2 mg artırılabilir. Eğer kan şekeri hedef eğerlerin üzerinde kalıyorsa günlük 1,8 mg'a kadar doz artırılabilir. 


\section{malar \\ Liraglutidin monoterapide etkinliğini gösteren çalış-}

Liraglutid monoterapide plasebo ile karşılaştırıldığında, liragulitidin $1,90,1,25,0,65 \mathrm{mg}$ dozlarında HbA1C'nin 7 mg'a ulaşma oranı $\% 46,48,38$ iken, plasebo grubunda $\% 5$ olarak bildirilmektedir (Vilsbøll, 2007). Liraglutidinin (1,2 veya $1,8 \mathrm{mg}$ ) glimeperid $(8 \mathrm{mg})$ ile karşılaştırıldığ 52 haftalık çalışmada HbA1C'nin 7 mg'a ulaşma oranı liraglutid grubunda $\% 43,5$ iken, glimeprid grubunda $\% 28$ bulunmuştur. HbA1C'deki azalma liraglutidde \%0,84 ve 1,14 iken glimeperid \%0,51 bulunmuştur (Garber ve ark., 2009). Liraglutide metformin, thiazolidinedione (TZD) veya sülfonilüre ile kombinasyonda kullanıldığında da HbA1C'de \%1-1,5'luk ve plaseboya göre anlamlı düşme görülmektedir (Nauck ve ark., 2009; Marre ve ark., 2009; Russell-Jones ve ark., 2009; Zinman ve ark., 2009).

Liraglutid plasebo, sitagliptin veya glimepridle karşılaştırıldığında 1,4-3,5 kg kilo kaybına neden olur (Russell-Jones ark., 2009; Zinman ark., 2009). En önemli yan etkisi bulant1, kusma ve diyaredir. \%10-40 görülür (Russell-Jones ve ark., 2009; Zinman ve ark., 2009).

3900 hastayı içeren beş liraglutid çalışmasında, liraglutid kullanan 7 hastada pankreatid bildirilmiştir. Diğer diyabet ilaçlarını kullananlarda bir vakada pankreatid görülmüştür. Şu anki bilgilere göre yine de GLP-1 analoglarının direkt pankreatidle ilişkilendirmek için veriler yetersizdir. Bulantılı veya bulantısız karın ağrısı olan hastalarda pankreatid düşünülmeli ve doğrulanıncaya kadar liraglutid kesilmelidir. liraglutid kullanımında hipoglisemi riski düşüktür. Bir çalışmada minor hipoglisemi liraglutid monoterapisi alan hastaların \%10'unda hafif hipoglisemi gözlenmiştir. Glimeperid alan grupta \%24 olarak görülmüştür (Garber, 2009).

Sıçan çalışmalarında, liraglutidin benign ve malign tiroid C-hücre tümörleri ile birlikteliğine rastlanmıştır. Bu konu ile ilgili veri kısıtlıdır. GLP-1 reseptörleri aracılığı ile ilgili tür spesifik bir fenomen olabilir. İnsanlarda bu türe bir etki olup olmadığı bilinmemektedir. İnsanlarda sıçanlardan daha az C hücresi vardır ve insan C hücrelerinde GLP-1 reseptörleri daha azdır (Bjerre Knudsen ve ark., 2010). Kısa süreli insan çalışmalarında kalsitonin seviyelerinde değişiklik gözlenmemiştir fakat medüller kanserin gelişmesi uzun yıllar alabilir. Liraglitid veya diğer GLP-1 reseptörü agonistlerinin C hücreleri üzerine potansiyel etkileri ile ilgili insanlarda daha ileri çalışmalara ihtiyaç vardır. Yeterli veriler oluşana kadar, medüller tiroid kanseri veya Multıbl endokrin neoplazi (MEN) 2 A veya 2 B aile hikâyesi olanlarda liragulutidin kullanımı önerilmemektedir.

Liraglutid kullanımıyla antikor gelişimi orijinal moleküle yüksek homoloji göstermesi nedeniyle daha düşüktür (\%4-13).

\section{Eksenatid LAR}

Cilt altı exenatidin yavaş salınımlı formu olan, eksenatid LAR geliştirme aşamasındadır. Yarı ömrü ortalama iki haftadır. Tip 2 diyabetik hastalarda metformin ve/veya diyet ve egzersiz alan grupla karşılaştırıldığında HbA1C seviyelerinde azalmaya neden olmuştur (Kim ve ark., 2007; Diamant ve ark., 2010; Bergenstal 2010). Kırk beş hastalık bir çalışma grubuna 0,8 ve 2,0 mg dozunda haftada bir kez 15 hafta süresince uygulandığında, plasebo grubuna kıyasla $(\% 0,4) \mathrm{HbA} 1 \mathrm{C}$ seviyesini $\% 1,4$ ve $\% 1,7$ oranında azaltmıştır. 2,0 mg grubun- da hastaların \%86'sında HbA1C \%7nin altına çekilmiştir (Kim ve ark., 2007).

Eksenatid-LAR kullanan hastalarda anti-eksenadin antikor gelişiminin, klasik eksenatid gruplarına göre daha yüksek titrede olduğu görülmüş, ancak antikor titresinin 16. haftadan sonra düşmeye başladığı dikkati çekmiştir. Enjeksiyon yerinde kaşıntı eksenatid-LAR grubunda daha sık görülen bir yan etkidir (\%19'a \%1)( Drucker ve ark., 2008).

\section{Tip 2 diyabet ve DPP-4 inhibitörleri}

Antidiyabetik ajanların yeni bir sınıfı olan bu ilaçlardan, ilk olarak 2006 DPP-4 inhibitörü olan sitagliptin ortaya çıkmıştır. Diğer DPP-4 inhibitörleri vildagliptin, saxagliptin, alogliptin ve denagliptin'dir.

\section{Sitagliptin}

Sitagliptin bir DPP-4 inhibitorüdür. Sulfonilüre (SÜ), metformin veya TZD'lere tek ajan olarak iyi cevap vermeyenlerde ikinci bir ajan olarak ve metformin SÜ ikili tedavisine yeterli cevap vermeyenlerde üçüncü ilave ajan olarak veya başlangıç tedavisi olarak tip 2 diyabet tedavisi için uygun olabilir. 2006 yılında kullanımı dünyada yaygın olarak onaylanan sitagliptinin genellikle önerilen dozu günde tek doz 100mg tablet şeklindedir. Böbrek yetmezliğinde doz azaltılması gereklidir. Glomeral filtrasyon hızı (GFR) 30-50 $\mathrm{ml} / \mathrm{dk}$ olanlarda $50 \mathrm{mg}$ 'a, GFR $30 \mathrm{ml} / \mathrm{dk}$ olanlarda $25 \mathrm{mg}$ 'a azaltılmalıdır (Bergman 2007).

Sitagliptin monoterapide kullanıldığında HbA1C'de \%0,6'lık bir düşüş sağlamıştır (Raz, 2006). Sitagliptinin metforminle kombine edildiği 24 haftalık bir çalışmada HbA1C de \%1,4-1,9'luk düşüş tespit edilmiştir. Sitagliptin metformin, TZD veya sülfonilüre ile kombinasyon tedavisinde de etkilidir. Bu ajanlardan herhangi birine ek olarak verildiğinde HbA1C'de \%0,45 ile \%1'lik bir düşüş beklenebilir. Bir çalışmada HbA1C düşürücü etkisi glipizid ile benzer bulunmuştur (Nuck ve ark., 2007).

SÜ ile yapılmış bir kombinasyon çalışmasında hipoglisemi sıklı̆̆ $\% 12,3$ ve monoterapide ya da metformin ve TZD kombinasyonu rejimlerinde \%0,5-2,2 arasinda hipoglisemi görülmüştür (Raz ve ark., 2008).

Sitagliptin-metformin tek bir tablette kombinasyonu mevcutttur (50 mg/500 mg ve $50 \mathrm{mg} / 1000 \mathrm{mg}$ ).

GLP-1 analoglarının aksine gastrointestinal yan etkileri daha nadirdir. Bulantı en s1k görülen yan etkidir (\%0,5-5,5). DPP-4 enzim inhibitörlerinin immün sistem üzerine etkilerinin olup olmadığı henüz aydınlatılamamıştır. Sitagliptin alan hastalarda baş ağrısı, nazofarinjit ve üst solunum yolu enfEksiyonlarının daha sık görüldüğü, üriner sistem enfeksiyonlarının 1,5 kat arttığ 1 bildirilmektedir (Hermansen ve ark., 2007; Amori ve ark 2007).

Sitagliptinin vücuttan atılımı \%80 değişmeden idrar yoluyla olur. Orta derecede böbrek yetmezliğinde (30>GFR->50 $\mathrm{ml} / \mathrm{dk}$ ) günlük doz $50 \mathrm{mg}$ 'a, ciddi yetmezliklerde (GFR <30 $\mathrm{ml} / \mathrm{dk}$ ) ve son dönem böbrek yetmezliğinde $25 \mathrm{mg}$ 'a düşülmelidir. Hafif ve orta dereceli karaciğer bozukluklarında doz ayarlmasına gerek yoktur. Şiddetli karaciğer yetmezliğinde kullanımı ile ilgili veri yoktur. Gebelik katogorisi C'dir. Gebe kadınlarda kullanımı ile ilgili yeterli veri yoktur. Hayvanlar üzerinde yapılan çalışmalar stagliptinin sütle atıldığını göstermektedir. Bu nedenle laktasyon döneminde kullanılmamalidir. 


\section{Saxagliptin}

Saxagliptin tip 2 diyabette başlangıç tedavisi olarak kullanılabileceği gibi SÜ, metformin ve TZD gibi tek bir ajana yeterli cavap alınamayan vakalarda ikinci ajan alarak ilave edilebilir. Saxagliptinin genellikle kullanılan dozu günde bir kez 2,5 veya 5 mgdır. GFR $\leq 50 \mathrm{~mL} / \mathrm{dk}$ olan böbrek yetmezlikli hastalarda 2,5 mg dozda önerilmektedir. Saxagliptin monoterapide HbA1C de azalmaya yol açar (Rosenstock ve ark., 2009). Yirmi dört haftalık bir çalışmada saxagliptin $(2,5,5$, veya $10 \mathrm{mg} /$ gün) plasebo ile karşılaştırıldığında saxagliptin HbA1C de 0,4, 0,5, azalmaya yol açmıştır (Rosenstock ve ark., 2009). Saxagliptin metformin, SÜ veya TZD kombinasyon tedavisinde de etkilidir (DeFronzo ve ark., 2009; Jadzinsky ve ark., 2009).

\section{Vildagliptin}

Vildagliptin, DPP-4 üzerine yüksek afiniteli bir inhibitör etki sergilemektedir ve kendisi bu enzimin bir substratıdır. Vildagliptin hızlı bağlanma fazını takip eden yavaş-sıkı bağlanma fazından oluşan komptetif ve geri dönüşlü bağlanma gösterir. Vildagliptin DPP-4 için yüksek derecede seçicidir ve çok yavaş ayrışma hızları ile sıkı bağlanma kinetiği sergilemektedir. Vildagliptin/DPP-4 kompleksi ortalama 55 dakikalık bir yarı ömürle ayrışmaktadır (Burkey ve ark., 2006).

Vildagliptin insülini arttırarak ve glukagon sekresyonunu azaltarak adacık hücresi fonksiyonunu güçlendirmektedir (He ve ark., 2007). Tip 2 DM'si olan hastalarda vildagliptin GLP-1 düzeylerini arttırmaktadır (Balas ve ark., 2007). Vildagliptin glukagon sekresyonunu baskılamaktadır. Çift kör bir çalışmada, tip 2 diabetes mellitusu olan hastalar; farklı günlerde tek bir vildagliptin $100 \mathrm{mg}$ veya plasebo dozu almışlar ve ardından 30 dakika sonra, bir öğün tolerans testinin (MTT) yürütülmesine imkan tanıyacak şekilde, radyoaktif olarak işaretlenmiş glukoz (75 g) içeren standart bir akşam yemeği yemişlerdir. MTT sırasında plazma örnekleri alınmıştır ve glukagon düzeyleri radyoimmün test ile hesaplanmıştır. Vildagliptin $100 \mathrm{mg}$ uygulaması MTT boyunca plaseboya göre anlamlı olarak daha büyük bir glukagon baskılanması ile ilişkilendirilmiştir $(\mathrm{P}<0,02)$; bu etkiler gece boyunca devam etmiştir (Balas ve ark., 2007).

Tip 2 DM, büyük ölçüde apoptoz artışına bağlı olarak, pankreas $\beta$-hücresi fonksiyonunda kademeli bir bozulma ve $\beta$-hücresi kütlesinde kayıp gözlenmektedir. Vildagliptinin $\beta$-hücre fonksiyonu ve glisemik kontrol kaybında düzelmeye neden olduğu 4 haftalık iki arındırma dönemini içeren 112 haftalık bir çalışmada gösterilmiştir. $\beta$-hücresi fonksiyonu göstergesi olan glukoz konsantrasyonuna göre insülin sekresyonu hızı (ISR/G) vildagliptin tedavisi ile iyileşmiştir. Bu koruyucu etkinin 2 yıllık tedavi süresince gözlendiği bildirilmiştir (Scherbaum ve ark., 2008). Vildagliptinin GLP-1' i arttırma etkisi $\alpha$-hücresinin glukoza karşı duyarlılığının iyileşmesine yol açmaktadır. Bu etkiyi değerlendiren hiperinsülinemik, glukoz klampı kullanılarak yapılan çalışmada hiperglisemik ve öglisemik kademeler boyunca, glukagon düzeyleri vildagliptin ile anlamlı olarak daha düşük bulunmuştur. Hipoglisemik kademeler boyunca ise, glukagon düzeyleri vildagliptin ile daha yüksek bulunmuştur. Vildagliptinin hiperglisemik durumlarda glukagonu azaltıcı ve hipoglisemik durumlarda glukagonu artırıcı etkisi GLP-1' in hücrelerinin glukoza karş1 glukoz duyarlılığını arttırıcı etkisi ile uyumlu olduğu şeklinde yorumlanmıştır. Vildagliptin düşük glukoz düzeylerinde gö- receli glukagon sekresyonu artışı vildagliptin tedavisi sırasında gözlenen düşük hipoglisemi riskinin nedenidir (Ahrén ve ark., 2008).

Sağlıklı bireylerde bir karşılaştırma yapıldığında, plaseboya karşı vildagliptin ile insülin veya glukoz düzeylerinde hiçbir değişim gözlenmezken, tip 2 diabetes mellitusu olan 14 hastada insülin iyileşmesi ve glukozun düşürülmesi aç1sindan belirgin fark bulunmuştur (Rosenstock ve ark., 2008). Vildagliptin glukoza karşı a- ve $\beta$-hücresi duyarlılığını iyileştirerek, enerji metabolizmasının kontrolüne yönelik normal fizyolojik mekanizmaları güçlendirmektedir (El-Ouaghlidi ve ark., 2007). Vildagliptin tedavisinin periferik glukoz kullanımı üzerine etkilerini değerlendirmek amacıyla yürütülen randomize, çift kör, plasebo kontrollü çapraz geçişli çalışmada, tip 2 diabetes mellitusta Tip 2 DM'si olan hastalar (HbA1C \% 7,1) 6 hafta boyunca vildagliptin veya plasebo ve ardından 6 hafta boyunca diğer terapiyi almak üzere randomize edilmişlerdir. Her tedavi döneminden sonra, hastalar 2 günlük bir metabolik test dönemine ve 2 adımlı 20 (LO) ve $90(\mathrm{HI}) \mathrm{mU} / \mathrm{m} 2 /$ dak insülin infüzyonu glukoz klempine girmişlerdir. HI insülin infüzyonu sırasında $(80 \mathrm{mU} / \mathrm{m} 2 /$ dak $)$, vildagliptin plaseboya karşı sistemik glukoz kullanımını anlamlı olarak artırmıştır (6,1 vs 5,4 mg/kg/dak; $\mathrm{P}<0,05)$. Bu çalışma glukoz toksisitesinin en düşük düzeyde olduğu (hafif hiperglisemi) ve yüksek insülin içerikli koşullar altında (eşzamanlı olarak düşük glukagon ve baskılanmış hepatik glukoz üretimi) yapıldığından, glukoz kullanımındaki artış olasılıkla periferik insülin duyarlılığındaki lipotoksik bir iyileşmeye atfedilebilir. Bu veriler günde iki kez uygulanan $50 \mathrm{mg}$ vildagliptinin insülin ile uyarılan glukoz kullanımını iyileştirerek glukoza karşı insülin duyarlılığını artırdığını göstermektedir (Azuma ve ark., 2008) .

\section{DPP-4 inhibitorlerinin karşılaştırılması}

DPP-4 inhibitörlerini direkt olarak karşılaştıran bir çalışma olmamasına rağmen, bir meta analiz sitagliptin ile plasebo veya vildagliptin ile plasebo karşılaştırmalarında benzer etkiler olduğunu bildirmektedir (Amori ve ark., 2007). İkinci bir meta analizde sitagliptin ve vildagliptin çalışmalarında benzer bulgular rapor edilmektedir (Richter, 2008). Sinırlı veri olmasına rağmen saxagliptin verileri de benzer görülmektedir.

DPP-4 inhibitörleri orta derece HbA1C'de düzelmeye neden olurlar. Bununla beraber uzun dönem güvenirlik, mortalite, diyabetik komplikasyonlar ve yaşam kalitesi üzerine yeter sayıda çalışmaları yoktur.

\section{Yan etkiler}

DPP-4 inhibitörleri kısa dönem çalışmalarda iyi tolere edilirler. Hipoglisemi riski ve kilo üzerine etkileri yoktur. DPP-4 inhibitörleri GLP-1'ler için spesifik olmasına rağmen en uzun dönem DPP-4 inhibisyonunun sonuçları bilinmemektedir. Kısa dönem çalışmalarda rapor edilmemelerine rağmen, DPP-4 inhibisyonunun immun sistem üzerine etkileri ile ilgili endişeler mevcuttur. Bununla beraber bir meta analizde sitagliptin ve vildagliptin çalışmalarında yan etki olarak nazofarinjit riskinde (risk ratio [RR] 1,2, 95\% CI 1,0-1,4), üriner sistem enfeksiyonları (RR 1,5, 95\% CI 1,0-2,2) ve baş ağrısında (RR 1,4, 95\% CI 1,1-1,7) küçük bir artış rapor edilmektedir (Amori 2007).

Pazarlama sonrası raporlarda sitagliptin kullanan has- 
talarda akut pankreatit bildirilmiştir. Bu bulgular eksenatid lanan hastalarda tanımlanan pankreatit bulguları ile benzerdir. Günümüzde mevcut bilgilerle GLP-1 aracıllğı ile oluşan pankreatitin bir sınıf etki olduğu konusu açık eğildir. Pankreatiti düşündürecek karın ağrısı olan hastalarda sitagliptin veya sitagliptin metformin kesilmelidir. Pankreatit hikâyesi olan hastalarda sitagliptin kullanılıyorsa yakından takip edilmelidir

Yaygın olmamasına rağmen, vildagliptin kullanan hastalarda hepatik disfonksiyona neden olabilir. Vildagliptin kullanmadan önce ve ilk bir yıl üç ayda bir karaciğer fonksiyon testleri değerlendirilmelidir (Ligueros-Saylan ve Foley, 2010). Eğer AST veya ALT normalin üç katından fazla artış gösterirse vildagliptin kesilmelidir.
Bazı DPP-4 inhibitorleri (vildagliptin ve saxagliptin) kullanımı sırasında hayvanlarda preklinik çalışmalarda deri reaksiyonları (kırmızı renk değişikliği ve şişme, kabarma ve yüksek dozlarda nekroz ile ciltte pullanma) gözlenmiştir (Ligueros-Saylan ve Foley, 2010). Deri lezyonları vildagliptinin önerilen terapotik dozlarının 4-6 katı kullanan gönüllülerde de gözlenmiştir.

Pazarlama sonrası raporlarda, sitagliptin hipersensitivite reaksiyonlar1-Stevens-Johnson sendromu dahil, anafilaksi, anjiyoödem ve eksfolyatif cilt hastalıkları bildirilmiş̧ir. Sitagliptin daha önceki maruziyetinde hipersensitivite reaksiyonu veren hastalarda kontrendikedir. DPP-IV inhibitörleri C-hücre fizyolojisi veya büyümesi üzerine insanlarda veya hayvanlarda yapılmış çalışma yoktur.

\section{KAYNAKLAR}

Abraham, E.J., Leech, C.A., Lin, J.C., Zulewski, H., Habener, J.F., 2002. Insulinotropic hormone glucagon-like peptide-1 differentiation of human pancreatic islet-derived progenitor cells into insulin-producing cells. Endocrinology. 143, 3152-3161.

Ahrén, B., Pacini, G., Foley, J.E., Schweizer, A., 2005. Improved meal-related beta-cell function and insulin sensitivity by the dipeptidil peptidaz-IV inhibitor vildagliptin in metformin-treated patients with type 2 diabetes over 1 year. Diabetes Care. 28, $1936-1940$.

Ahrén, B., 2005. Inhibition of dipeptidil peptidaz-4 (DPP-4) a novel approach to treat type 2 diabetes. Curr. Enzyme Inhib. 1, 65-73.

Amori, R.E., Lau, J., Pittas, A.G., 2007. Efficacy and safety of incretin therapy in type 2 diabetes: Systematic review and meta-analysis. JAMA. 298, 194-206.

Azuma, K., Rádiková, Z., Mancino, J., Toledo, F.G., Thomas, E., Kangani, C., Dalla, M.C., Cobelli, C., Holst, J.J., Deacon, C.F., He, Y., Ligueros-Saylan, M., Serra, D., Foley, J.E., Kelley, D.E., 2008. Measurements of islet function and glukoz metabolism with the dipeptidil peptidaz-4 inhibitor vildagliptin in patients with type 2 diabetes. J. Clin. Endocrinol. Metab. 93, 459-464.

Balas, B., Baig, M.R., Watson, C., Dunning, B.E., Ligueros-Saylan, M., Wang, Y., He, Y.L., Darland, C., Holst, J.J., Deacon, C.F., Cusi, K., Mari, A., Foley, J.E., DeFronzo, R.A., 2007. The dipeptidil peptidaz IV inhibitor vildagliptin suppresses endogenous glucose production and enhances islet function after single-dose administration in type 2 diabetic patients. J. Clin. Endocrinol Metab. 92, 1249-1255.

Barnett, A.H., Burger. J., Johns, D., Brodows, R, Kendall, D.M., Roberts, A., Trautmann, M.E., 2007. Tolerability and efficacy of exenatide and titrated insulin glargine in adult patients with type 2 diabetes previously uncontrolled with metformin or a sulfonylurea: A multinational, randomized, open-label, two-period, crossover noninferiority trial. Clin. Ther. 29, 2333-2348.

Bergman, A.J., Cote, J., Yi, B., Marbury, T., Swan, S.K., Smith, W., Gottesdiener, K., Wagner, J., Herman, G.A. 2007. Effect of renal insufficiency on the pharmacokinetics of sitagliptin, a dipeptidyl peptidase-4 inhibitor. Diabetes Care. 30, 1862-1864.

Bjerre Knudsen, L., Madsen, L.W., Andersen, S., Almholt, K., de Boer, A.S., Drucker, D.J., Gotfredsen C, Egerod F.L, Hegelund, A.C., Jacobsen, H., Jacobsen, S.D., Moses, A.C., Mølck, A.M., Nielsen, H.S., Nowak, J., Solberg, H., Thi, T.D., Zdravkovic, M., 2010. Glucagon-like Peptide-1 receptor agonists activate rodent thyroid C-cells causing calcitonin release and C-cell proliferation Endocrinology. 151, 1473-1486.

Bosi, E., Camisasca, R.P., Collober, C., Rochotte, E., Garber, A.J., 2007. Effects of vildagliptin on glucose control over 24 weeks in patients with type 2 diabetes inadequately controlled with metformin. Diabetes Care. 30, 890-895.

Bunck, M.C., Diamant, M., Cornér, A., Eliasson, B., Malloy, J.L., Shaginian, R.M., Deng, W., Kendall, D.M., Taskinen, M.R., Smith, U., Yki-Järvinen, H., Heine, R.J., 2009. One-year treatment with exenatide improves beta-cell function, compared with insulin glargine, in metformin-treated type 2 diabetic patients: a randomized, controlled trial. Diabetes Care. 32, 762-768.

Buse, J.B., Rosenstock, J., Sesti, G., Schmidt, W.E., Montanya, E., Brett, J.H., Zychma, M., Blonde, L; LEAD-6 Study Group. 2009. Lirglutide once a day versus exenatide twice a day for type 2 diabetes: a 26-week randomised, parallel-group, multinational, open-label trial (LEAD-6). Lancet. 4;374, 39-47.

Charbonnel, B., Karasik, A., Liu, J., Wu, M., Meininger, G., Sitagliptin Study 020 Group. 2006. Efficacy and safety of the dipeptidyl peptidase-4 inhibitor sitagliptin added to ongoing metformin therapy in patients with type 2 diabetes inadequately controlled with metformin alone. Diabetes Care. 29, 2638-2643.

Deacon, C.F., Nauck, M.A., Toft-Nielsen, M., Pridal, L., Willms, B., Holst, J.J., 1995. Both subcutaneously and intravenously administered glucagon-like peptide I are rapidly degraded from the NH2-terminus in type II diabetic patients and in healthy subjects. Diabetes. 44, 11261131.

DeFronzo, R.A., Hissa M.N., Garber, A.J., Luiz, Gross, J., Yuyan Duan, R., Ravichandran, S., Chen, R.S., Saxagliptin 014 Study Group. 2009. The efficacy and safety of saxagliptin when added to metformin therapy in patients with inadequately controlled type 2 diabetes with metformin alone. Diabetes Care. 32, 1649-1655.

DeFronzo, R.A., Okerson, T., Viswanathan, P., Guan, X., Holcombe, J.H., MacConell, L., 2008. Effects of exenatide versus sitagliptin on postprandial glucose, insulin and glucagon secretion, gastric emptying, and caloric intake: a randomized, cross-over study. Curr. Med. Res. Opin. 24, 2943-2952.

DeFronzo, R.A., Ratner, R.E., Han, J., Kim, D.D., Fineman, M.S., Baron, A.D., 2005. Effects of exenatide (exendin-4) on glycemic control and weight over 30 weeks in metformin-treated patients with type 2 diabetes. Diabetes Care. 28, 1092-1100.

Dejager, S., Razac, S., Foley, J.E., Schweizer, A., 2007. Vildagliptin in drug-naïve patients with type 2 diabetes: a 24-week, double-blind, randomized, placebo-controlled, multiple-dose study. Horm. Metab. Res. 39, 218-223.

Delmeire, D., Flamez, D., Moens, K., Hinke, S.A., Van Schravendijk, C., Pipeleers, D., Schuit, F., 2004. Prior in vitro exposure to GLP-1 with or without GIP can influence the subsequent beta cell responsiveness. Biochem. Pharmacol. 68, 33-39.

Diamant, M., Van, Gaal, L., Stranks, S., Northrup, J., Cao, D., Taylor, K., Trautmann, M., 2010. Once weekly exenatide compared with insulin glargine titrated to target in patients with type 2 diabetes (DURATION-3): an open-label randomised trial. Lancet. 375, $2234-2243$. 
Drucker, D.J., Buse, J.B., Taylor, K., Kendall, D.M., Trautmann, M., Zhuang, D., Porter, L. ; DURATION-1 Study Group. 2008. Exenatide once weekly versus twice daily for the treatment of type 2 diabetes: A randomised, open-label, non-inferiority study. Lancet. 372, 1240-1250.

Drucker, D.J., 2003. Enhancing incretin action for the treatment of type 2 diabetes. Diabetes Care. 26, 2929-2940.

Drucker, D.J., 1998. Glucagon-like peptides. Diabetes. 47, 159-169.

Egan, J.M., Clocquet, A.R., Elahi, D., 2002. The insulinotropic effect of acute exendin-4 administered to humans: comparison of nondiabetic state to type 2 diabetes. J. Clin. Endocrinol. Metab. 87, 1282-1290.

Elbrønd, B., Jakobsen, G., Larsen, S., Agersø, H., Jensen, L.B., Rolan, P., Sturis, J., Hatorp, V., Zdravkovic, M., 2002. Pharmacokinetics, pharmacodynamics, safety, and tolerability of a single-dose of NN2211, a long-acting -like peptide 1 derivative, in healthy male subjects. Diabetes Care. 25, 1398-1404.

El-Ouaghlidi, A., Rehring, E., Holst, J.J., Schweizer, A., Foley, J., Holmes, D., Nauck, M.A., 2007. The dipeptidyl peptidase 4 inhibitor vildagliptin does not accentuate glibenclamide-induced hypoglycemia but reduces glucose-induced glucagon-like peptide 1 and gastric inhibitory polypeptide secretion. J. Clin. Endocrinol. Metab. 92, 4165-4171.

Elrick, H., Stimmler, 1., Hlad, C.J. JR., Arai, Y., 1964. Plasma insulin response to oral and intravenous glucose administration. J. Clin. Endocrinol. Metab. 24, 1076-1082.

Fagenholz, P.J., Castillo, C.F., Harris, N.S., Pelletier, A.J., Camargo, C.A., Jr. 2007. Increasing United States hospital admissions for acute pancreatitis, 1988-2003. Ann. Epidemiol. 17, 491-497.

Farilla, L., Bulotta, A., Hirshberg, B., Li, Calzi, S., Khoury, N., Noushmehr, H., Bertolotto, C., Di, Mario, U., Harlan, D.M., Perfetti, R., 2003. Glucagon-like peptide 1 inhibits cell apoptosis and improves glucose responsiveness of freshly isolated human islets. Endocrinology. 144, 5149-5158.

Farilla, L., Hui, H., Bertolotto, C., Kang, E., Bulotta, A., Di, Mario, U., Perfetti, R., 2002. Glucagon-like peptide-1 promotes islet cell growth and inhibits apoptosis in Zucker diabetic rats. Endocrinology. 143, 4397-4408.

Fineman, M.S., Shen, L.Z., Taylor, K., Kim, D.D., Baron, A.D., 2004. Effectiveness of progressive dose-escalation of exenatide (exendin-4) in reducing dose-limiting side effects in subjects with type 2 diabetes. Diabetes Metab. Res. Rev. 20, 411-417.

Flint, A., Raben, A., Astrup, A., Holst, J.J. 1998. Glucagon-like peptide 1 promotes satiety and suppresses energy intake in humans. J. Clin. Invest. 101,5 515-520.

Forsmark, C.E., Baillie, J., 2007. AGA Institute Clinical Practice and Economics Committee; AGA Institute Governing Board. AGA Institute technical review on acute pancreatitis. Gastroenterology. 132, 2022-2044.

Frossard, J.L., Steer, M.L., Pastor, C.M., 2008 . Acute pancreatitis. Lancet. 371, 143-152.

Garber, A., Henry, R., Ratner, R., Garcia-Hernandez, P.A., Rodriguez-Pattzi, H., Olvera-Alvarez, I., Hale, P.M., Zdravkovic, M., Bode B; LEAD-3 (Mono) Study Group. 2009. Liraglutide versus glimepiride monotherapy for type 2 diabetes (LEAD-3 Mono): a randomised, 52week, phase III, double-blind, parallel-treatment trial. Lancet. 373, 473-481.

He, Y.L., Wang, Y., Bullock, J.M., Deacon, C.F., Holst, J.J., Dunning, B.E., Ligueros-Saylan, M., Foley, J.E., 2007. Pharmacodynamics of vildagliptin in patients with type 2 diabetes during OGTT. J. Clin. Pharmacol. 47, 633-641.

Heine, R.J., Van, Gaal, L.F., Johns, D., Mihm, M.J., Widel, M.H., Brodows, R.G.; GWAA Study Group. 2005. Exenatide versus insulin glargine in patients with suboptimally controlled type 2 diabetes: a randomized trial. Ann. Intern. Med. 143, 559-569.

Hermansen, K., Kipnes, M., Luo, E., Fanurik, D., Khatimi, H., Stain, P., Stagliptin Study 035 Group. 2007. Efficay and Safety of the dipeptidyl peptidase-4 inhibitor, sitagliptin, in patients with type 2 diabetes mellitus inadequately conrolled on glimepiride alone or on glimepiride and metformin Diabetes Obes. Metab. 9, 733-745.

Jadzinsky, M., Pfützner, A., Paz-Pacheco, E., Xu, Z., Allen, E., Chen, R., CV181-039 Investigators. 2009. Saxagliptin given in combination with metformin as initial therapy improves glycaemic control in patients with type 2 diabetes compared with either monotherapy: A randomized controlled trial. Diabetes Obes. Metab. 11, 611-622.

Kendall, D.M., Riddle, M.C., Rosenstock, J., Zhuang, D., Kim, D.D., Fineman, M.S., Baron, A.D., 2005. Effects of exenatide (exendin-4) on glycemic control over 30 weeks in patients with type 2 diabetes treated with metformin and a sulfonylurea. Diabetes Care. 28, 1083-1091.

Kieffer, T.J., McIntosh, C.H., Pederson, R.A., 1995. Degradation of glucose-dependent insulinotropic polypeptide and truncated glucagon-like peptide 1 in vitro and in vivo by dipeptidyl peptidase IV. Endocrinology. 136, 3585-3596.

Kim, D., MacConell, L., Zhuang, D., Kothare, P.A, Trautmann, M., Fineman, M., Taylor, K., 2007. Effects of once-weekly dosing of a longacting release formulation of exenatide on glucose control and body weight in subjects with type 2 diabetes. Diabetes Care. 30, $1487-1493$.

Kjems, L.L., Holst, J,J,, Vølund, A., Madsbad, S., 2003. The influence of GLP-1 on glucose-stimulated insulin secretion: effects on beta-cell sensitivity in type 2 and nondiabetic subjects. Diabetes. 52, 380-386.

Klonoff, D.C., Buse, J.B., Nielsen, L.L., Guan, X., Bowlus, C.L., Holcombe, J.H., Wintle, M.E., Maggs, D.G., 2008. Exenatide effects on diabetes, obesity, cardiovascular risk factors and hepatic biomarkers in patients with type 2 diabetes treated for at least 3 years. Curr. Med. Res. Opin. 24, 275-286.

Kolterman, O.G., Buse, J.B., Fineman, M.S., Gaines, E,, Heintz, S., Bicsak, T.A., Taylor, K., Kim, D., Aisporna, M., Wang, Y., Baron, A.D., 2003. Synthetic exendin-4 (exenatide) significantly reduces postprandial and fasting plasma glucose in subjects with type 2 diabetes. J. Clin. Endocrinol. Metab. 88, 3082-3089.

Kolterman, O.G., Kim, D.D., Shen, L., RuggIcs, J.A., Nielsen, L.L., Fineman, M.S., Baror1, A.D., 2005. Pharmacokinetics, pharmacodynamics, and safety of exenatide in patients with type 2 diabetes mellitus.Am. J. Health Syst. Pharm. 62, 173-181.

Larsen, J., Hylleberg, B., Ng, K., Damsbo, P., 2001. Glucagon-like peptide-1 infusion must be maintained for 24 h/day to obtain acceptable glycemia in type 2 diabetic patients who are poorly controlled on sulphonylurea treatment. Diabetes Care. 24, 1416-1421.

Larsson, H., Holst, J.J., Ahrén, B., 1997. Glucagon-like peptide-1 reduces hepatic glucose production indirectly through insulin and glucagon in humans.Acta Physiol. Scand. 160, 413-422.

Ligueros-Saylan, M., Foley, E., Coururier, A., Kathy, W., 2010. An assessment of adverse effects of vildagliptin versus comparators on the liver, the pancreas, the immune system, the skin and in patients with impaired renal function from a large pooled database of Phase II and III clinical trials. Diabetes Obes. and Metab. 12, 495-509.

Marre, M., Shaw, J., Brändle, M., Bebakar, W.M., Kamaruddin, N.A., Strand, J., Zdravkovic, M., Le, Thi ,T.D., Colagiuri, S.; LEAD-1 SU study group. 2009. Liraglutide, a once-daily human GLP-1 analogue, added to a sulphonylurea over 26 weeks produces greater improvements in glycaemic and weight control compared with adding rosiglitazone or placebo in subjects with type 2 diabetes (LEAD-1 SU). Diabet Med. $26,268-278$. 
Moretto, T.J., Milton, D.R., Ridge, T.D., Macconell, L.A., Okerson, T., Wolka, A.M., Brodows, R.G., 2008. Efficacy and tolerability of exenatide monotherapy over 24 weeks in antidiabetic drug-naive patients with type 2 diabetes: A randomized, double-blind, placebo-controlled, parallel-group study. Clin Ther. 30, 1448-1460.

Nauck, M., Frid, A., Hermansen, K., Shah, N.S., Tankova, T., Mitha, I.H., Zdravkovic, M., Düring, M., Matthews, D.R.; LEAD-2 Study Group. 2009. Efficacy and safety comparison of liraglutide, glimepiride, and placebo, all in combination with metformin, in type 2 diabetes: the LEAD (liraglutide effect and action in diabetes)-2 study. Diabetes Care. 32, 84-90.

Nauck, M.A., Duran, S., Kim, D., Johns, D., Northrup, J., Festa, A., Brodows, R., Trautmann, M., 2007. A comparison of twice-daily exenatide and biphasic insulin aspart in patients with type 2 diabetes who were suboptimally controlled with sulfonylurea and metformin: A noninferiority study. Diabetologia. 50, 259-267.

Nauck, M.A., Meininger, G., Sheng, D., Terranella, L., Stein, PP.; Sitagliptin, Study 024 Group. 2007. Efficacy and safety of the dipeptidyl peptidase-4 inhibitor, sitagliptin, compared with the sulfonylurea, glipizide, in patients with type 2 diabetes inadequately controlled on metformin alone: a randomized, double-blind, non-inferiority trial. Diabetes Obes Metab. 9, 194-205.

Nauck, M.A., Wollschläger, D., Werner, J., Holst, J.J., Orskov, C., Creutzfeldt, W., Willms, B., 1996. Effects of subcutaneous glucagon-like peptide 1 (GLP-1 [7-36 amide]) in patients with NIDDM. Diabetologia. 39, 1546-1553.

Noel, R.A., Braun, D.K., Patterson, R.E., Bloomgren, G.L., 2009. Increased risk of acute pancreatitis and biliary disease observed in patients with type 2 diabetes: a retrospective cohort study. Diabetes Care. 32, 834-838.

Pi-Sunyer, F.X., Schweizer, A., Mills, D., Dejager, S.. 2007. Efficacy and tolerability of vildagliptin monotherapy in drug-naïve patients with type 2 diabetes. Diabetes Res Clin Pract. 76, 132-138.

Pratley, R.E., Jauffret-Kamel, S., Galbreath, E., Holmes, D., 2006. Twelve-week monotherapy with the DPP-4 inhibitor vildagliptin improves glycemic control in subjects with type 2 diabetes. Horm. Metab. Res. 38, 423-428.

Ratner, R.E., Maggs, D., Nielsen, L.L., Stonehouse, A.H., Poon, T., Zhang, B., Bicsak, T.A., Brodows, R.G., Kim DD. 2006. Long-term effects of exenatide therapy over 82 weeks on glycaemic control and weight in over-weight metformin-treated patients with type 2 diabetes mellitus. Diabetes Obes. Metab. 8, 419-428.

Raz, I., Chen, Y., Wu, M., Hussain, S., Kaufman, K.D., Amatruda, J.M., Langdon, R.B., Stein, P.P., Alba, M., 2008. Efficacy and safety of sitagliptin added to ongoing metformin therapy in patients with type 2 diabetes. Curr. Med. Res. Opin. 24, 537-550.

Raz, I., Hanefeld, M., Xu, L., Caria, C., Williams-Herman, D., Khatami, H.; Sitagliptin Study 023 Group. 2006. Efficacy and safety of the dipeptidyl peptidase-4 inhibitor sitagliptin as monotherapy in patients with type 2 diabetes mellitus. Diabetologia. 49, $2564-2571$.

Richter, B., Bandeira-Echtler, E., Bergerhoff, K., Lerch, C.L., 2008. Dipeptidyl peptidase-4 (DPP-4) inhibitors for type 2 diabetes mellitus. Cochrane Database Syst. Rev. 16, CD006739.

Riddle, M.C., Henry, R.R., Poon, T.H., Zhang, B., Mac, S.M., Holcombe, J.H., Kim, D.D., Maggs, D.G., 2006. Exenatide elicits sustained glycaemic control and progressive reduction of body weight in patients with type 2 diabetes inadequately controlled by sulphonylureas with or without metformin. Diabetes Metab. Res. Rev. 22, 483-491.

Ristic, S., Byiers, S., Foley, J., Holmes, D., 2005. Improved glycaemic control with dipeptidyl peptidase-4 inhibition in patients with type 2 diabetes: vildagliptin (LAF237) dose response. Diabetes Obes. Metab. 7, 692-698.

Rosenstock, J., Aguilar-Salinas, C., Klein, E., Nepal, S., List, J., Chen, R., CV181-011 Study Investigators, 2009. Effect of saxagliptin monotherapy in treatment-naïve patients with type 2 diabetes. Curr. Med. Res. Opin. 25, 2401-2411.

Rosenstock, J., Brazg, R., Andryuk, P.J., Lu, K., Stein, P. Sitagliptin Study 019 Group. 2006. Efficacy and safety of the dipeptidyl peptidase-4 inhibitor sitagliptin added to ongoing pioglitazone therapy in patients with type 2 diabetes: A 24-week, multicenter, randomized, doubleblind, placebo-controlled, parallel-group study. Clin. Ther. 28, 1556-1568.

Rosenstock, J., Foley, J.E., Rendell, M., Landin-Olsson, M., Holst, J.J., Deacon, C.F., Rochotte, E., Baron, M.A., 2008. Effects of the dipeptidyl peptidase-IV inhibitor vildagliptin on incretin hormones, islet function, and postprandial glycemia in subjects with impaired glucose tolerance. Diabetes Care. 31, 30-35.

Rosenstock, J., Reusch, J., Bush, M., Yang, F., Stewart, M. Albiglutide Study Group. 2009. Potential of albiglutide, a long-acting GLP-1 receptor agonist, in type 2 diabetes: A randomized controlled trial exploring weekly, biweekly, and monthly dosing. Diabetes Care. 32, $1880-1886$.

Rosenstock, J., Sankoh, S., List, J.F., 2008. Glucose-lowering activity of the dipeptidyl peptidase-4 inhibitor saxagliptin in drug-naive patients with type 2 diabetes. Diabetes Obes. Metab. 10, 376-386.

Russell-Jones, D., Vaag, A., Schmitz, O., Sethi, B.K., Lalic, N., Antic, S., Zdravkovic, M., Ravn, G.M., Simó, R., 2009. Liraglutide Effect and Action in Diabetes 5 (LEAD-5) met+SU Study Group Liraglutide vs insulin glargine and placebo in combination with metformin and sulfonylurea therapy in type 2 diabetes mellitus (LEAD-5 met+SU): A randomised controlled trial. Diabetologia. 52, 2046-2055.

Scherbaum, W.A., Schweizer, A., Mari, A., Nilsson, P.M., Lalanne, G., Wang, Y., Dunning, B.E., Foley, J.E., 2008. Evidence that vildagliptin attenuates deterioration of glycaemic control during 2-year treatment of patients with type 2 diabetes and mild hyperglycaemia. Diabetes Obes. Metab. 10, 1114-1124.

Steinberg, W., Tenner, S., 1994. Acute pancreatitis. N. Engl. J. Med. 330,1198-1210.

Stoffers, D.A., Desai, B.M., DeLeon, D.D., Simmons, R.A., 2003. Neonatal exendin-4 prevents the development of diabetes in the intrauterine growth retarded rat. Diabetes. 52, 734-740.

Stoffers, D.A., Kieffer, T.J., Hussain, M.A., Drucker, D.J., Bonner-Weir, S., Habener, J.F., Egan, J.M., 2000. Insulinotropic glucagon-like peptide 1 agonists stimulate expression of homeodomain protein IDX-1 and increase islet size in mouse pancreas. Diabetes. 49, $741-748$.

Tang-Christensen, M., Larsen, P.J., Göke, R., Fink-Jensen, A., Jessop, D.S., Møller, M., Sheikh, S.P., 1996 . Central administration of GLP-1-(736) amide inhibits food and water intake in rats. Am.J. Physiol. 271, 848-856.

Thorens, B., Porret, A., Bühler, L., Deng, S.P., Morel, P., Widmann, C., 1993 . Cloning and functional expression of the human islet GLP-1 receptor. Demonstration that exendin-4 is an agonist and exendin-(9-39) an antagonist of the receptor. Diabetes. 42, 1678-1682.

Tourrel, C., Bailbe, D., Lacorne, M., Meile, M.J., Kergoat, M., Portha, B., 2002. Persistent improvement of type 2 diabetes in the Goto-Kakizaki rat model by expansion of the beta-cell mass during the prediabetic period with glucagon-like peptide-1 or exendin-4 Diabetes. 51, 14431452

Unger, R.H., 1974 . Alpha- and beta-cell interrelationships in health and disease. Metabolism. 23, 581-593.

Vella, A., Bock, G., Giesler, P.D., Burton, D.B., Serra, D.B., Saylan, M.L., Dunning, B.E., Foley, J.E., Rizza, R.A., Camilleri, M., 2007. Effects of dipeptidyl peptidase-4 inhibition on gastrointestinal function, meal appearance, and glucose metabolism in type 2 diabetes. Diabetes. 56, $1475-1480$. 
Vilsbøll, T., Holst, J.J., 2004. Incretins, insulin secretion and type 2 diabetes mellitus. Diabetologia. 47, 357-366.

Vilsbøll, T., Krarup, T., Madsbad, S., Holst, J.J., 2002. Defective amplification of the late phase insulin response to glucose by GIP in obese Type II diabetic patients. Diabetologia. $45,1111-1119$.

Vilsbøll, T., Zdravkovic, M., Le-Thi, T., Krarup, T., Schmitz, O., Courrèges, J.P., Verhoeven, R., Bugánová, I., Madsbad, S., 2007. Liraglutide, a long-acting human glucagon-like peptide-1 analog, given as monotherapy significantly improves glycemic control and lowers body weight without risk of hypoglycemia in patients with type 2 diabetes. Diabetes Care. 30, 1608-1610.

Xu, G., Stoffers, D.A., Habener, J.F., Bonner-Weir, S., 1999. Exendin-4 stimulates both beta-cell replication and neogenesis, resulting in increased beta-cell mass and improved glucose tolerance in diabetic rats. Diabetes. 48, 2270-2276.

Young, A.A., Gedulin, B.R., Bhavsar, S., Bodkin, N., Jodka, C., Hansen, B., Denaro, M., 1999. Glucose-lowering and insulin-sensitizing actions of exendin-4: Studies in obese diabetic $(\mathrm{ob} / \mathrm{ob}, \mathrm{db} / \mathrm{db})$ mice, diabetic fatty Zucker rats, and diabetic rhesus monkeys (Macaca mulatta). Diabetes. 48, 1026-1034.

Zander, M., Madsbad, S., Madsen, J.L., Holst, J.J., 2002. Effect of 6-week course of glucagon-like peptide 1 on glycaemic control, insulin sensitivity, and beta-cell function in type 2 diabetes: A parallel-group study. Lancet. 359, 824-830.

Zinman, B., Gerich, J., Buse, J.B., Lewin, A., Schwartz, S., Raskin, P., Hale, P.M., Zdravkovic, M., Blonde, L.; LEAD-4 Study Investigators. 2009. Efficacy and safety of the human glucagon-like peptide-1 analog liraglutide in combination with metformin and thiazolidinedione in patients with type 2 diabetes (LEAD-4 Met+TZD). Diabetes Care. 32, 1224-1230.

Zinman, B., Hoogwerf, B.J., Durán, García, S., Milton, D.R., Giaconia, J.M., Kim, D.D., Trautmann, M.E., Brodows, R.G., 2007.The effect of adding exenatide to a thiazolidinedione in suboptimally controlled type 2 diabetes: a randomized trial. Ann. Intern. Med. 146, 477-485. 